Proc. Estonian Acad. Sci. Eng., 2003, 9, 3, 220-242

\title{
Fast ferries as a new key forcing factor in Tallinn Bay
}

\author{
Tarmo Soomere $^{\mathrm{a}}$, Jüri Elken ${ }^{\mathrm{a}}$, Jüri Kask ${ }^{\mathrm{a}}$, Sirje Keevallik ${ }^{\mathrm{a}}$, Tarmo Kõuts ${ }^{\mathrm{a}}$, \\ Jaan Metsaveer ${ }^{\mathrm{b}}$, and Pearu Peterson ${ }^{\mathrm{c}}$ \\ a Marine Systems Institute, Tallinn Technical University, Akadeemia tee 21, 12618 Tallinn, Estonia; \\ tarmo@phys.sea.ee \\ b Department of mechanics, Tallinn Technical University, Ehitajate tee 5, 19086 Tallinn, Estonia \\ c Institute of Cybernetics, Tallinn Technical University, Akadeemia tee 21, 12618 Tallinn, Estonia
}

Received 6 May 2003, in revised form 14 June 2003

\begin{abstract}
The role of ship-generated waves in the total wave activity in Tallinn Bay, a semienclosed basin of the Gulf of Finland, is analysed. The heights of ship waves are moderate. Since the seabed in the vicinity of the shoreline is mostly covered with a pebble and cobble pavement which protects the shore from further erosion, the influence of the ship waves is negligible near the shoreline. Owing to the high density of fast ferry traffic, the annual mean energy of ship waves is $5-8 \%$ from the wind wave energy and the ship-induced wave energy flux (wave power) is $18-35 \%$ from the wind wave power. The highest components of ship wakes have the heights about $1 \mathrm{~m}$ and frequently periods of $10-15 \mathrm{~s}$. Such waves do not occur in natural conditions in the area in question. They cause unusually high near-bottom velocities at the depths of 5-20 m. Thus, the fast ferry traffic is a new forcing component of vital impact on the local ecosystem that may cause considerable intensification of beach processes as well as enhanced vertical mixing in the water body. It may have significant influence on the aquatic biota.
\end{abstract}

Key words: fast ferries, ship wash, Gulf of Finland, wave measurements.

\section{INTRODUCTION}

During the last years, the waves from fast ferries have become a problem of growing concern in inland channels, rivers, and shallow straits. The prime reason is continuing introduction of evermore faster high-speed ship services. As a consequence of the higher speed, the vessel wakes also have a longer period than wakes caused by conventional ships $\left[{ }^{1}\right]$ and may lead to substantial wave action in shallow water environments. In restricted water, the critical speed effects play a great role in the wash problems. Large high-speed craft, carrying passengers 
and vehicles, do not produce only higher wake waves than conventional vessels and smaller fast vessels, but also fundamentally different wave systems when sailing at specific speeds in shallow areas $\left[^{2}\right]$.

An important factor in many wash problems is the amplification of long ship waves while they proceed from deep into shallow water. This amplification is determined by the ratio of the wavelength to the water depth. Therefore it may be much stronger for the long waves generated by a fast ferry than for the shorter ones of a conventional ship. Consequently, the fast ferry waves, while perhaps hardly visible in deep water, have occasionally been found to cause violent impacts on the coast while waves from conventional ships, perhaps having a larger amplitude in deep water, undergo a much smaller amplification $\left[{ }^{3,4}\right]$. Specific bottom topography may strongly contribute to the wash effects; for example, there may be effects of wave reflections and/or focusing due to the variable waterway cross-section $\left[{ }^{5}\right]$.

Originally, the more serious wash problems predominantly had to do with coastal or bank erosion, damage to moored vessels or constructions, and danger to the general public using beaches and low coastal paths, caused by wave patterns generated in the open sea or in confined waters $\left[{ }^{3,6,7}\right]$. The occurrence of harmful effects of ship waves depends on various aspects of the wave system and on the local situation. This makes it impossible to indicate a single criterion governing the occurrence or absence of dangerous wash effects.

An issue of particular concern in vulnerable environment is that wakes from a high-speed craft can cause serious environmental problems (such as severe shoreline erosion, ecological disturbance, harm to the aquatic wildlife, damage to structures and archaeological sites) as well as safety problems for navigation and for users of the beach and nearshore in confined waters $\left[{ }^{6-10}\right]$. The ship's wave system contains a massive amount of energy that can seriously damage the marine environment. The wash from a passing craft must be regarded as a pollutant like, for example, the greenhouse effect gases $\left.{ }^{[1,12}\right]$ according to articles 1(4) and 194 of the UN Convention on the Law of the Sea.

Issues relating to high-speed craft wakes were not addressed until regular operation of such vessels had caused complex coastal management problems. Detailed studies of various aspects of fast ferry operation have been carried out during the last decade $\left[^{3,5-11,13-16}\right]$. Starting from 1997, several countries and communities (for example, Denmark, Sweden, and New Zealand) have introduced strict regulations of the fast ferry traffic. It is remarkable that the regulations are primarily based on wave height criteria $\left[{ }^{3,10}\right]$. Due to the great interest in wake-wash effects, a considerable amount of recent research effort has been devoted to the design of low-wash ships and to acquiring reliable data for the validation of their effect $\left[{ }^{17-19}\right]$. Also full-scale measurements have been carried out, aiming at deriving recommendations for safe ship operation in sensitive areas $\left[{ }^{20,21}\right]$.

It is generally believed that the ship wakes are negligible or sporadic in the open sea areas where the fast ship traffic is sparse and natural waves are 
frequently much higher than the wakes. This assumption is indeed true for coasts exposed to high tidal waves or in places where wind wave loads greatly exceed those of anthropogenic origin $\left[{ }^{22}\right]$. In these areas, the main threat of ship wakes is the sudden appearance of high or breaking waves in the coastal zone in otherwise calm conditions $\left[{ }^{7,11,16}\right]$.

However, in sheltered non-tidal sea areas (such as the Black Sea or the Baltic Sea) the near-bottom velocities are governed by the local winds and currents. The particular geometry of specific sea areas and peculiarities of the local wind regime play a major role in the natural wave activity. For example, the sea winds and wave trains in elongated basins are frequently directed along the basin axis $\left.{ }^{23-26}\right]$. Semi-open bays of such basins may have a very mild natural wave regime and may be particularly vulnerable to the changes in the wave activity.

Tallinn Bay is an example of a well-sheltered sea region (about $10 \times 20 \mathrm{~km}$ ) in the central part of the Gulf of Finland, Baltic Sea. A map of the Baltic Sea basin is reproduced on the back cover and a detailed map of Tallinn Bay on the inside back cover of this issue; for an overview of physical oceanography of the gulf see $\left[{ }^{27}\right]$. The area between the Estonian and Finnish capitals, Tallinn and Helsinki, apparently has the heaviest fast ferry traffic among the open sea areas of the Baltic Sea since 2000. Different high-speed ships cross the gulf daily nearly 70 times during high season. A variety of different types of high-speed ships sail there, including $100 \mathrm{~m}$ long monohulls, wave-piercing catamarans, and hydrofoils. The resulting abrupt increase of the anthropogenic wave load may affect the intensity of coastal processes essentially.

This paper describes a part of the results of a recent study of the impact of ship waves in the coastal areas of Tallinn Bay $\left[{ }^{28}\right]$. The goal was to answer the intriguing question whether the ship waves can play a key role in the coastal processes and be dangerous to the ecosystem of the bay. The answer, somewhat surprisingly, is yes. In essence, it is based on the evidence that fast ferries frequently generate waves with specific properties. Such waves do not exist in the area in question in natural conditions.

The principal role of wakes of fast ferries does not become evident in the immediate vicinity of the shoreline where natural waves dominate. Owing to the unusual length of wake waves compared to wind waves in this particular area, wakes have the largest influence in the deeper part of the coastal zone. At the depths of 5-20 m, the influence of a typical wake is comparable with or even exceeds that of the natural waves of the most violent storms. The extension and many properties of this influence are still unclear and have to be addressed in further studies.

The detailed descriptions of various aspects of the influence of ship wakes, based on an intense field and theoretical study in 2001-2002 [ $\left.{ }^{28}\right]$, are presented in a number of recent papers. The bathymetry, the structure of bottom sediments and other geological features in areas potentially sensitive with respect to fast ferries wash were established in $\left[{ }^{29}\right]$. Specific features of the local wind regime were analysed in $\left[{ }^{26,30,31}\right]$. Wave climate of the bay was estimated on the basis of 
long-term wave hindcast with the use of a high-resolution version of the wave model WAM $\left[{ }^{32}\right]$. Results of an extensive field study of ship wave properties in different parts of the coast are presented in $\left[{ }^{33}\right]$. The possibility of emerging extremely high wave humps as a result of non-linear interactions of soliton-like wake waves $\left[{ }^{34}\right]$ and a qualitative description of a new phase of the coastal evolution $\left[{ }^{35}\right]$ were first reported in scientific literature in the framework of the described studies.

The current paper shortly delineates a few most important results of these studies. However, its main purpose is to quantify and to discuss the impact and the relative role of ship waves in the total wave activity. The comparison between natural and anthropogenic waves is mostly based on the analysis of the occurrence probability of the waves of different origin, on basic properties of the waves and wave-induced processes, and on energy density and its flux (wave power) in the coastal zone owing to wind waves and ship wakes.

Many deeply interesting properties of the ship wash, namely, the possibility of excitation of wave groups behaving like envelope solitons, the actual shape and nature of leading wake waves (whether they resemble KdV solitons or cnoidal waves), and their implicit influence on sea water properties (for example, changes of sea water optical properties through an increase of turbidity caused by wave-induced suspension of fine sediments) are still open and request further investigations.

\section{NATURAL WAVE REGIME AND GEOLOGICAL PREREQUISITES}

The natural wave regime of Tallinn Bay has been estimated on the basis of detailed analysis of the wind climate in the Gulf of Finland in $\left[{ }^{26}\right]$ and a simplified scheme for long-term wave hindcast with the use of a high-resolution multi-nested version of the WAM model $\left[{ }^{32}\right]$.

The prevailing winds in the Gulf of Finland are from SW and north, dominating in the whole Baltic Sea basin, and local east and west winds blowing along the axis of the gulf $\left[{ }^{26}\right]$. Typically, moderate and strong winds blow either from south or SW, or, in certain areas of the gulf, from east. Tallinn Bay is well sheltered from winds and waves coming from those directions. Only western winds may excite high waves in this area. As a result, the local wave climate is relatively mild compared to the open part of the Gulf of Finland and to the areas westward from the Island of Naissaar or eastward from the Viimsi Peninsula.

The angular structure of strong winds in the Gulf of Finland does not match the structure of all winds. Gales often blow from directions where winds generally are infrequent $\left[{ }^{26}\right]$. In particular, the strongest winds frequently blow from NW. Tallinn Bay is fully open to this direction and extreme NW winds may excite very high waves in its certain parts. This feature suggests that extreme wave heights in the bay are comparable with those in the open part of the Gulf of Finland. 
A recent analysis of the Kalbådagrund data (a caisson lighthouse located in the open part of the Gulf of Finland) and of a lately restored Naissaar data set [ $\left.{ }^{30}\right]$ confirmed the described results on the wind regime over the Gulf of Finland and specified some features of the local wind regime of Tallinn Bay $\left[{ }^{31}\right]$. The most probable wind direction in the area in question is SW. Moderate and strong winds have a secondary maximum in NE. SE winds are infrequent and weak.

The wind regime in Tallinn Bay can be adequately reconstructed by two points - one at the Tallinn harbour or in its vicinity, the other facing the open sea $\left.{ }^{31}\right]$. For these purposes, the Naissaar station (closed by now) was ideal. Somewhat surprisingly, the wind regime neither in the open part of the Gulf of Finland nor over Tallinn Bay cannot be restored on the basis of data from the meteorological stations at the southern coast of the gulf $\left[{ }^{26}\right]$. The discrepancy between their recordings and the open sea wind data is much larger than that reported in $\left[{ }^{36}\right]$ for the stations of the northern coast of the gulf, and at times becomes evident even in the directional structure of the winds.

Restoration of wind data over Tallinn Bay can be done rather successfully from Harku data (see map on the inside back cover) for the zonal wind component in winter, spring, and autumn. In July breeze and city winds do not permit to establish a trustworthy relationship. The meridional wind component can only be reconstructed during the cold season for the Tallinn harbour area, but not for the entrance of Tallinn Bay, thus, also not for the open part of the Gulf of Finland $\left[{ }^{31}\right]$. This analysis combined with the doubtful quality of the Naissaar wind data suggested that the wind statistics from Helsinki should be used to force the local wave model $\left[{ }^{32}\right]$.

Numerical simulations of the wave regime in Tallinn Bay show that the mainland and the surrounding islands well shelter the bay from waves coming from the dominating strong wind directions. Numerous shallow areas located at the entrances of the bay effectively damp waves, in particular, during strong storms. The joint influence of the shapes of the Gulf of Finland and the bay, the dominating wind directions, and the shallow areas is responsible for the particularly mild wave regime $\left[{ }^{32}\right]$.

The average wave properties have significant seasonal and spatial variability. For example, the annual mean wave energy flux density is $250-400 \mathrm{~W} / \mathrm{m}$ in the central area of the bay. During the calm spring and summer season it is less than $250 \mathrm{~W} / \mathrm{m}$ and during the relatively windy autumn and winter season up to $500 \mathrm{~W} / \mathrm{m}$. The highest waves occur in the vicinity of the Tallinn-Helsinki ship lane where significant wave height exceeds $2 \mathrm{~m}$ each year and may reach $4 \mathrm{~m}$ in extreme NNW storms. In specific coastal areas both wave energy and its flux are much less than in the centre of the bay $\left[{ }^{32}\right]$. Domains with exceptionally low wave intensity are located between the Island of Aegna and Rohuneeme harbour on the Viimsi Peninsula, and off SE coast of Naissaar. These areas apparently are the most vulnerable with respect to the fast ferries wakes.

A review of the geological setting of the coastal zone and the bottom deposits of the bay $\left[{ }^{29}\right]$, partially based on former investigations by the Geological Survey 
of Estonia $\left[{ }^{37}\right]$, enables to identify whether there are connections between the ship wakes and erosion and accumulation processes. The bedding conditions of sediments determine the formation of the sea floor topography, and this in turn influences currents and wave activity. Although the geological structure of the deeper part of the bottom of Tallinn Bay is generally known, the resolution of the existing data set $\left[{ }^{37}\right]$ is about $1 \mathrm{~km}$ and thus insufficient to describe features of bottom deposits in the coastal zone, directly affected by ship waves (depth $\leq 30$ $\mathrm{m}$, typical width $1-2 \mathrm{~km}$ ).

The geological field studies, performed from August to October 2001, covered a large part of the coasts of Tallinn Bay. Detailed studies were carried out in selected areas where high ship wave load was expected and that were potentially vulnerable to the increasing wave activity according to $\left[{ }^{28}\right]$. On the Viimsi Peninsula the observed shore section extends from Merivälja to Rohuneeme harbour. On the SW coast of Aegna detailed investigations were carried out northward of the Talneem Cape (length about $500 \mathrm{~m}$ ) where an about $2 \mathrm{~km}$ long eroded section was observed. On Naissaar about $7 \mathrm{~km}$ long section on its eastern coast was studied. Detailed investigations were performed north of the harbour (about $450 \mathrm{~m}$ ) and north of the Hülkari Cape (about $500 \mathrm{~m}$ ).

The beaches exposed to ship wakes were reviewed and the properties of erosion and accumulation processes were generally estimated. Sections where considerable changes occurred were photographed and mapped. In the detailed study areas the sea floor topography was surveyed and the bottom deposits were mapped according to their grain-size. In the Aegna investigation area 13 temporary piquettes were installed in order to register the changes in the shore scarp. In the observation area of the Viimsi Peninsula several drillholes were made. The underwater slope in the detailed study areas (sporadically also in other domains) was investigated also by diving. During the spring, summer, and autumn seasons in 2002, follow-up studies were performed in selected areas to detect the possible wave-induced changes $\left[{ }^{29}\right]$.

Residual deposits of variable grain size (boulders to silt) dominate in the coastal zone of Tallinn Bay. They overlie the bedrock or till and have been formed mainly as the result of wave activity. Water motion carries finer particles to the deeper sea, while coarse material remains in the surf zone and nearshore, thus forming a pavement on the seafloor. Such areas occur around Aegna, in Suurupi Strait, as well as in the coastal zone of the Kopli and Paljassaare peninsulas (see inside back cover). The pebble and boulder pavement with some sand fill is common on the western coast of the Viimsi Peninsula and on the eastern coast of Naissaar, where it covers almost the whole coastal zone to a depth of 5-6 m. Thus, various kinds of pavements that protect the nearshore area from the direct influence of waves occurring in typical wind conditions overwhelmingly dominate at the coasts of Tallinn Bay. Only in limited areas, covered with residual deposits, erosion and sediment transport take place.

The adjacent seaward zone, where sediment transport obviously occurs, is rather narrow and consists of medium sand. More seaward a zone of pebbles and 
cobbles follows, but the pavement alternates with gravel and sand. In the deeper part of the coastal zone the seafloor is covered by fine sand and silt but intense sediment accumulation is not observed.

The distribution of bottom sediments indicates that the contemporary marine sediments of the coastal zone are subject to intense wave wash and their transport processes are strongly influenced by wave activity. Abrupt increase of wave loads may cause substantial changes in sediment distribution. On the 15th of November 2001, during a severe storm, the water level in Tallinn Bay rose about $130 \mathrm{~cm}$ above the average and accompanying intense wave wash eroded parts of the backshore that normally were not subject to erosion. This storm caused changes in all the zones described above. A large amount of sediment material was released and distributed on the shore and nearshore. For example, near Pringi village the proximity of the shoreline is normally covered by a pebble and cobble pavement with few boulders, but after this storm there was also a lot of sand. After the storm the pavement, covering the till, was exposed and sand was present only sporadically. However, the usual pattern was restored in about $0.5-1$ year; for example, in summer 2002 the primary structure of the sediment distribution pattern (like it was in summer 2001) was already restored.

\section{GENERAL PROPERTIES OF SHIP WAVES}

When a ship passes through water surface, pressure variations at the water-air interface produce a series of waves. The first description of the resulting stationary wave pattern in deep water in terms of two sets of divergent waves (that move forward and out from the disturbance) and one set of transverse waves (that move in the direction of the disturbance, Fig. 1a) was given by Froude in $1877\left[{ }^{38}\right]$. The corresponding theory was constructed by lord Kelvin in $1887\left[{ }^{39}\right]$. The work was expanded by Havelock starting from $1908\left[{ }^{40}\right]$ to resolve some discontinuities in the Kelvin model and to include the effects of water depth (see, for example $\left[{ }^{1}\right]$ and bibliography therein). In reality the wash pattern is much
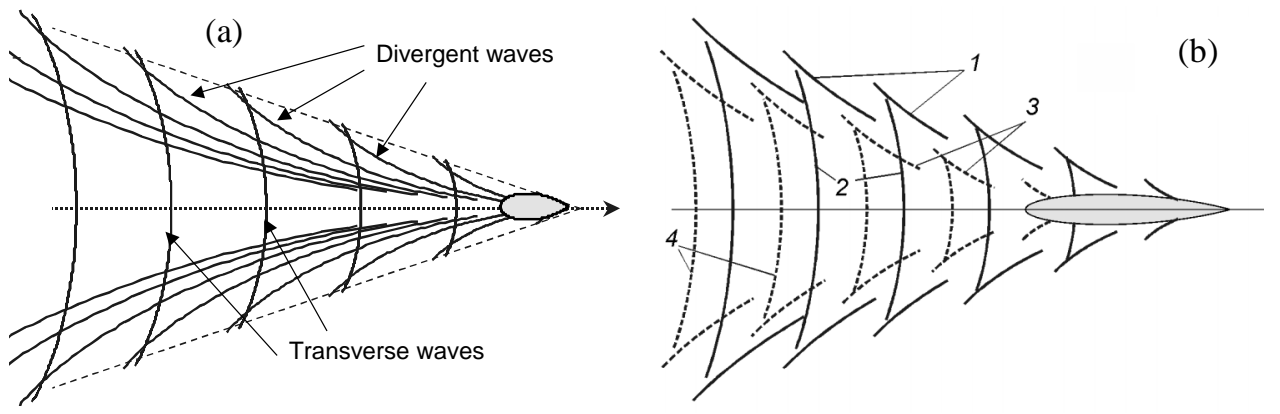

Fig. 1. (a) Wave crest pattern generated by a point pressure disturbance moving over deep water; (b) a realistic ship wave pattern: 1 - divergent bow waves, 2 - transversal bow waves, 3 - divergent stern waves, 4 - transversal stern waves. 
more complex $\left[{ }^{41}\right]$ and consists of a superposition of waves generated by different parts of the hull (Fig. 1b).

As the wave system remains steady with respect to the disturbance, the waves must have a phase velocity (celerity) $v_{c}=V \cos \theta$, where $V$ is the disturbance velocity and $\theta$ is the angle between the sailing line and the propagation direction of waves. If the ship sails in water of finite depth, the wave celerity additionally depends on the water depth and cannot exceed the value $\sqrt{g H}$ where $g$ is the gravity acceleration and $H$ is the water depth. This feature has a prominent effect on the wash pattern that is now variable and dependent on the depth Froude number $F_{h}=V / \sqrt{g H}$ of the moving disturbance. As the depth Froude number increases, the leading transverse and diverging waves are accentuated at the expense of the other waves.

The wave heights increase very rapidly if $F_{h} \rightarrow 1$. The increase is roughly proportional to $\left.F_{h}^{3}{ }^{1}\right]$. When $F_{h}=1$, the transverse and diverging waves form a single large wave with its crest normal to the sailing line and that travels with the same speed as the disturbance. There is a relatively wide transcritical speed range $0.84<F_{h}<1.15$ in realistic conditions, where no clear distinction between sub- and supercritical regimes is possible and a single large wave may emerge $\left.{ }^{[2}\right]$. For $F_{h}>1$ no transverse waves can exist and the resulting wave system consists of diverging waves radiating from the disturbance.

Beyond the critical speed the wave amplitudes decrease with increasing $F_{h}$ for a limited range of $F_{h}$, but still a few leading waves typically are higher than the preceding ones. The resulting wave system disperses slowly and remains more or less coherent up to the surf zone or even up to the coast. The viscous damping is negligible for long ship waves $\left[{ }^{1}\right]$ and the waves lose energy mostly owing to the crest-lengthening process or to wave-bottom interactions.

Water depth along the ship lane in Tallinn Bay varies from about $80 \mathrm{~m}$ at the entrance of the bay to about $20 \mathrm{~m}$ at the Pirita harbour - Katariina jetty line (see inside back cover and Fig. 2). The cruise velocity of fast ferries exceeds 35 knots $\left.{ }^{33}\right]$, thus, technically, they may readily sail in the near-critical velocity range $\sqrt{g H} \pm 15 \%$ between Tallinn passenger harbour and Aegna jetty.

For ships sailing southwards, the large single wave apparently disturbs the area from Katariina jetty to Pirita. For ships sailing towards Helsinki this wave may hit the southern coast of Aegna. Other locations of the coastal zone of Tallinn Bay are mostly affected by divergent waves. From those areas, the northern part of the Viimsi Peninsula and a small bay southwards from Pringi jetty are well sheltered from waves by a wide very shallow area. Only the part extending from Püünsi to Pringi jetty and possibly a short interval northwards from Miiduranna harbour are virtually vulnerable with respect to ship waves. The ship wave heights in the remote coastal zone of Naissaar are typically moderate. However, they may play a role in underwater processes because of their uncommon length.

As noted above, high-speed craft may produce fundamentally different wave systems than conventional vessels. Large ships, sailing at transcritical speeds in shallow areas, may excite soliton-like disturbances of the water surface $\left[{ }^{2}\right]$. Such 


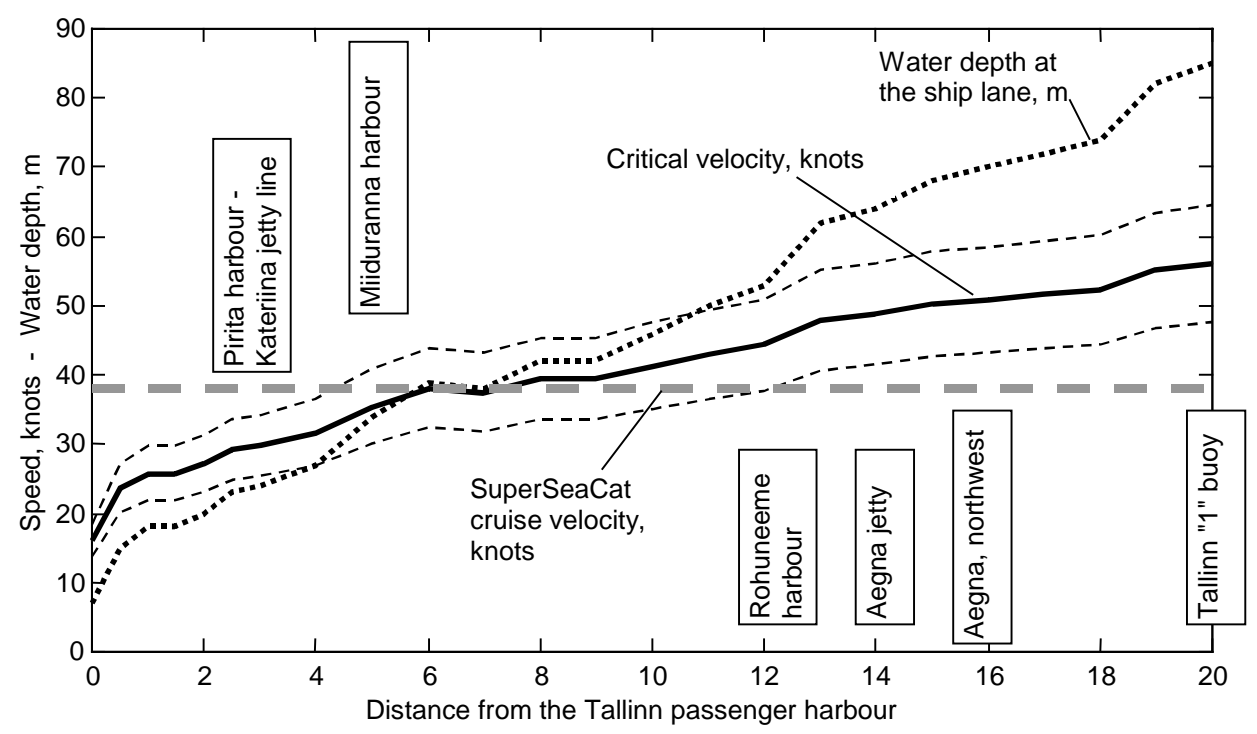

Fig. 2. Water depth on the ship lane of Tallinn Bay, the corresponding critical velocity, and the cruise velocity of SuperSeaCat IV from the passenger harbour entrance to Tallinn "1" buoy in the Gulf of Finland. The short-dashed lines show the limits of the transcritical velocity $( \pm 15 \%$ of the critical velocity).

disturbances generally are of moderate height $\left[{ }^{43}\right]$ and possess no immediate danger to the people or to the beach environment (except, possibly, in the breaking phase) although their runup on plane slopes considerably exceeds that of linear waves of comparable height $\left[{ }^{44}\right]$. However, interactions of soliton-like waves (created, for example, by two ships passing simultaneously) are fundamentally different from the superposition of linear waves $\left[{ }^{45}\right]$. Extreme surface elevations up to four times exceeding the amplitude of the interacting waves may occur $\left[{ }^{46}\right]$.

As an example of such interaction, joint evolution of two long-crested shallow water waves was analysed in the framework of the Kadomtsev-Petviashvili equation $\left[{ }^{34}\right]$. Substantial areas of extreme surface elevation may occur only if the heights of the interacting waves, their intersection angle, and the local water depth are specifically balanced. Thus, the fraction of sea surface, occupied by the particularly high wave humps, apparently is very small as compared with the area covered by intense wash $\left[{ }^{34}\right]$. By that reason, detecting of the extreme elevations in single-point measurements is unlikely. Still the non-linear amplification of wave heights in the crossing points of wave crests may be one of the reasons why superposition of critical wash, generated before and after turns, is mentioned as particularly dangerous $\left[{ }^{7}\right]$.

In populated or industrial areas, a possible hit of a non-linear particularly high wave hump at the entrance of a channel (harbour entrance, river mouth, etc.) may cause serious consequences. The reason is that this hump is basically different from the superposition of two linear wave trains. Linear waves continue to move 
in their original directions, and result in a system of interfering waves in the channel. If the interacting waves are of non-linear nature, their energy may be concentrated in one structure, the further behaviour of which is yet unclear.

Another specific type of waves that may be excited by fast ferries consists of highly monochromatic groups of relatively short waves with periods about $3 \mathrm{~s}$. They consist of about 10 crests and, because the period mistuning is very small, they remain compact for a long time. Although such groups have been mentioned in many studies of fast ferries $\left[{ }^{7,16,47}\right]$, their nature and behaviour (resembling that of envelope solitons) have not been considered in detail. Mathematically, they apparently can be described in terms of specific solutions to the non-linear Schrödinger equation $\left[{ }^{48}\right]$.

\section{WAVE MEASUREMENTS}

During the field experiments in 2002, the properties of both wind and ship waves were measured in several locations of the coastal zone of Tallinn Bay at the depths of 5-6 m, about 300-400 $\mathrm{m}$ from the coastal line, and at a distance of $2-8 \mathrm{~km}$ from the ship lane $\left[{ }^{33}\right]$. The measurement sites (see map on the inside back cover) were chosen near the coastal areas that were estimated as the most vulnerable with respect to the ship waves $\left[{ }^{29}\right]$.

The periods of energy-containing ship waves were expected to vary from $3 \mathrm{~s}$ up to tens of seconds $\left[{ }^{7}\right]$ suggesting that pressure sensors can be used for ship wave measurements. The sensor of a wave recorder (SBE26, Sea-Bird Electronic) was mostly positioned at the depth of 2-2.5 $\mathrm{m}$ that allowed to record the wave components with the periods $>1.5 \mathrm{~s}$. This technique well represents wave periods and heights but does not allow to reproduce the details of the wave profile. The recordings depict natural wave properties in greatly different wind conditions (including strong gales) in 15 days and trace more than 500 ship wakes $\left[{ }^{33}\right]$.

Both field experiments and computer simulations $\left[{ }^{32}\right]$ show that the significant wave height in Tallinn Bay does not exceed $20-25 \mathrm{~cm}$ and the dominating wave periods are only $1-2 \mathrm{~s}$ in weak wind conditions (wind speed $\leq 5 \mathrm{~m} / \mathrm{s}$ ). In moderate wind conditions $(6-7 \mathrm{~m} / \mathrm{s})$ the significant wave height increases to $50-60 \mathrm{~cm}$. The dominating wave periods are about $2-3 \mathrm{~s}$. The fraction of swell is mostly small. Winds $8-10 \mathrm{~m} / \mathrm{s}$ cause the wave heights of $70-90 \mathrm{~cm}$ with a wide spectrum with more or less uniform energy distribution between waves with periods $2.5-5 \mathrm{~s}$. Typically a distinguishable swell with periods of $5-6 \mathrm{~s}$ is also present.

During the initial phase of gales, waves with periods of 2.5-3.5 s dominate provided the gale is preceded by calm conditions. However, if moderate and/or strong winds precede the gale, swell may be significant. The maximum wave height is reached within 5-6h from the beginning of the gale. Its value in a specific point of the bay strongly depends on the particular wind speed and direction. By that time, maximum energy have waves with periods of $4-5 \mathrm{~s}$. 
Further on, wave spectrum widens towards longer waves, spectral maximum reaches 5-6 s within about 8-9 $\mathrm{h}$ and an intense swell with periods up to $7 \mathrm{~s}$ forms a part of the wave field. The height of such swell waves generally is well below $1 \mathrm{~m}$. Waves with periods exceeding $7 \mathrm{~s}$ are very infrequent $\left[{ }^{49}\right]$.

Several witnesses claimed that ship wakes may be as high as $4 \mathrm{~m}$ in specific areas, in particular, near Aegna jetty. However, visual estimates of wash patterns by experienced personnel together with preliminary experiments in 2001 showed no waves with the heights exceeding $2 \mathrm{~m}$. However, frequently higher than $1 \mathrm{~m}$ waves occured at depths of $7-10 \mathrm{~m}\left[{ }^{28}\right]$. Such large wave heights mean that the waves may already break at the depth of $3 \mathrm{~m}$ (where the wave properties should be measured according to the regulations in Denmark and New Zealand $\left[{ }^{50,51}\right]$ ). To avoid strong shoaling effects and possible wave breaking in the vicinity of the pressure cell, the measurement sites were chosen at depths of about 5-6 m. The results of this measurement series also confirmed that ship waves may cause essential increase of water turbidity $\left[{ }^{28}\right]$. The largest ship waves apparently were asymmetric: the shape of the pressure signal suggested that the wave crest was much higher than the trough although the waves were not breaking.

The passenger ships sailing in Tallinn Bay can be divided into three sets according to their wash properties $\left[{ }^{33}\right]$. The first set form hydrofoils Jaanika and Laura, capable of sailing at supercritical speeds. The height of their wake generally does not exceed $10 \mathrm{~cm}$ in the coastal areas of the bay. The wake can be identified only in the neighbourhood of Katariina jetty (because it lies close to the trajectory of the hydrofoils) but it apparently is not of importance even there.

The second set form classical ferries sailing at moderate depth Froude numbers and producing waves with typical heights of $20-30 \mathrm{~cm}$ and maximum heights of $40 \mathrm{~cm}$. Their typical wave periods are 3-4.5 s. Their wake fast disperses and is not identifiable in the coastal area of Naissaar (where only wakes of ships passing through Suurupi Strait were distinguishable from the natural background). Finnjet (Silja Line) is equipped with powerful gas turbine engines and is capable to sail at the critical speed. When operating in Tallinn Bay, she uses speeds comparable to that of the classical ferries and typically generates waves with moderate heights and periods.

The third group form catamarans Nordic Jet, Baltic Jet, AutoExpress and AutoExpress 2, and monohull SuperSeaCat IV, having cruise speeds of 36-38 knots. In what follows they are called fast ferries. Frequently it was not possible to distinguish wakes of similar ships from each other and below we use the double names Nordic/Baltic Jet and AutoExpress/2 for these ships. They all fall into the classification as high-speed craft according to IMO regulations $\left[{ }^{52}\right]$. They may operate at speeds near to or exceeding the critical speed. The heights of their wash frequently exceeds $1 \mathrm{~m}$ in the coastal zone of the bay whereas the periods of their highest components are about $10-15 \mathrm{~s}$. Waves with such properties do not exist in natural conditions in the area in question. 


\section{WAKES OF FAST FERRIES}

\subsection{Structure of the wake patterns}

A typical wake of a fast ferry, operating at high speeds, consists of two or three wave groups. They arrive at the eastern coast of the bay about 5-10 min after the ship has passed, last about ten minutes and consist of several tens of wave crests $\left[{ }^{33}\right]$. The first group contains waves with periods of $15-9 \mathrm{~s}$ (the longer waves arrive first) and has a duration of 3-4 min. The second group arrives a few minutes after the first one, contains waves with periods of 9-7 $\mathrm{s}$ and has a duration of 4-5 min. An underlying swell wave, probably representing transverse waves $\left[{ }^{7}\right]$, is not considered separately here because its height generally is much smaller than that of other groups. The third wave group consists of relatively short practically monochromatic waves with periods of 3-4 s. Its duration is about one minute, it resembles an envelope soliton $\left[{ }^{48}\right]$, and it was recognized only in a relatively small number of recordings. It was repeatedly present in the wake of SuperSeaCat IV but seldom in wakes of catamarans.

The western coast of Tallinn Bay lies at a distance of about $8 \mathrm{~km}$ from the ship lane. The wave groups have to travel over a sea area with highly variable bathymetry. Strong dispersion of the leading wave groups, jointly with energy dissipation owing to wave-bottom interaction, makes these groups long and relatively gentle. The first and the second wave group normally last for 15-30 minutes. The duration of a wake frequently exceeds one hour. The height of individual waves is moderate and in many cases they are not distinguishable onboard small boats. However, they are clearly identifiable from the pressure signal as well as by the divers and the people standing in shallow water. The optional third group is remarkably monochromatic and remains compact although it arrives about one hour after the leading waves. Its duration is less than $2 \mathrm{~min}$.

The wave groups are thus predominantly localized in space, time, and frequency domains. The long-wave part of a ship wake is thoroughly visible in the pressure signal and can be easily distinguished from digitally filtered water surface time series. The third wave group is at times masked by wind waves in both pressure and water surface time series. It is hardly identifiable in spectral picture, in particular, if a longer recording interval is used, because of its very short duration. Owing to its highly monochromatic nature, it can be detected with the use of appropriate band-pass filters. A promising technology for the ship wake analysis is the wavelet technique that apparently allows to identify the wave groups in both time and frequency domain.

There were only a few cases when waves with periods exceeding $20 \mathrm{~s}$ occurred whereas their height did not exceed $10 \mathrm{~cm}$. Such waves generally appear when ships sail in the transcritical regime during a longer time $\left.{ }^{7}\right]$. Their absence apparently is caused by the complex bathymetry of Tallinn Bay where the transcritical regime is possible only in a few segments of the ship lane. Also, these waves strongly interact with the seafloor and may fast lose their energy. 
The leading waves of a wake typically are the highest and have the largest periods. The maximum height of the long-wave components with periods $>7 \mathrm{~s}$ reaches $80-110 \mathrm{~cm}$ every day, depending on the particular site. The waves of the second group are always smaller than the leading waves. The heights of the short components of a wake generally are even smaller. Yet the short-wave groups may reach $90 \mathrm{~cm}$ and at times (in particular, often at Naissaar) contain the highest waves of the wake. This feature apparently is related with their soliton-like nature.

\subsection{Wave heights}

The leading waves of maximum height $(108 \mathrm{~cm})$ were caused by two ships, jointly passing the SE coast of Aegna in calm conditions $\left[{ }^{33}\right]$. At the western coast of Aegna the height of the long-wave components reached $92 \mathrm{~cm}$. The highest wave was also produced jointly by two ships sailing to Helsinki. Somewhat lower waves generally occur at the coast of the Viimsi Peninsula, where they did not exceed $80 \mathrm{~cm}$. As different from other sites, the highest waves were created by a single ship sailing to Tallinn. In the more remote coastal zone of Naissaar the highest long-period waves reached $47 \mathrm{~cm}$.

Long waves produced by a single ship apparently are the highest at the southern coast of Aegna. They may frequently exceed $1 \mathrm{~m}$ near Aegna jetty. They apparently are excited by ships sailing occasionally at speeds close to the critical velocity in the central part of Tallinn Bay. This hypothesis well explains the strong asymmetry of wave heights with respect to the sailing direction at this site $\left[{ }^{33}\right]$. Yet all wakes traced near Aegna apparently were generated in the high speed subcritical regime according to the classification of $\left[{ }^{7}\right]$. Since fast ferries may reach the critical speed at the ship lane, single waves created in the transcritical regime and with the height of about $2 \mathrm{~m}$ potentially may hit the Aegna jetty area.

The highest long waves generated by a single ship at the western coast of Aegna were about $60 \mathrm{~cm}$. At the coast of the Viimsi Peninsula, the heights of wakes of single ships normally are $40-50 \mathrm{~cm}$, the above-described $80 \mathrm{~cm}$ high single ship waves being exceptional. In the more remote coastal zone of Naissaar the long wave height reaches typically $25-35 \mathrm{~cm}$.

The maximum wave heights and their asymmetry with respect to the sailing direction at other measurement sites generally were much smaller than near Aegna jetty. Apparently, those sites are mostly affected by divergent waves. For example, the maximum wave height at the western coast of Aegna was about $20 \%$ less than near Aegna jetty although the western site was closer to the ship lane, it was fully open seawards, and about six time more passings were recorded there $\left[{ }^{33}\right]$.

Particularly high waves may occur owing to superposition of several systems of ship waves and the natural background. The highest recorded ship-generated waves were $2.3 \mathrm{~m}$ at the western coast of Aegna, $1.75 \mathrm{~m}$ at Pringi, $1.2 \mathrm{~m}$ at Aegna jetty, and $70 \mathrm{~cm}$ at Naissaar. The waves possibly were at the breaking 
stage. Their periods were 3-5 s (except the $1.2 \mathrm{~m}$ high wave at Aegna), thus they cannot be related to particularly high wave humps occurring as a result of nonlinear interactions of single soliton-like waves $\left[{ }^{34}\right]$. The contribution of wind waves into the highest waves was modest. For example, the significant height of wind waves was about $50 \mathrm{~cm}$ when the above-mentioned $2.3 \mathrm{~m}$ high waves were recorded. Thus the height of the ship waves was, at least, $150 \mathrm{~cm}$. Waves with the height of $1.75 \mathrm{~m}$ occurred when the significant wind wave height was $15-20 \mathrm{~cm}$.

\subsection{Wake energy distribution}

The major part of the energy of the wakes of fast ferries was concentrated in wave components with the periods exceeding 6-7 s (Fig. 3) that is in accordance with other studies $\left[^{7}\right]$. Although the wave energy of single wakes was sharply peaked, on average the wave energy was distributed much more evenly among the wave components $\left[{ }^{33}\right]$. The energy distributions have a characteristic twopeaked shape. The peaks apparently correspond to the first and the second group of the wake patterns. The share of waves with periods of 3-5 s (including those generated by hydrofoils and conventional ships) was small (see energy distribution near Aegna jetty in Fig. 3). This occurs because high and short waves appear relatively seldom and the duration of their groups is short.

The peak for the longest wave components in the average energy spectrum at the western coast of Aegna contained two sharp sub-peaks corresponding to waves with periods of $11-12 \mathrm{~s}$ and $9-10 \mathrm{~s}\left[{ }^{33}\right]$. Fast ferries apparently sail at their cruise speeds near this site and the sharp peaks apparently indicate the periods of the leading waves for different ship types.

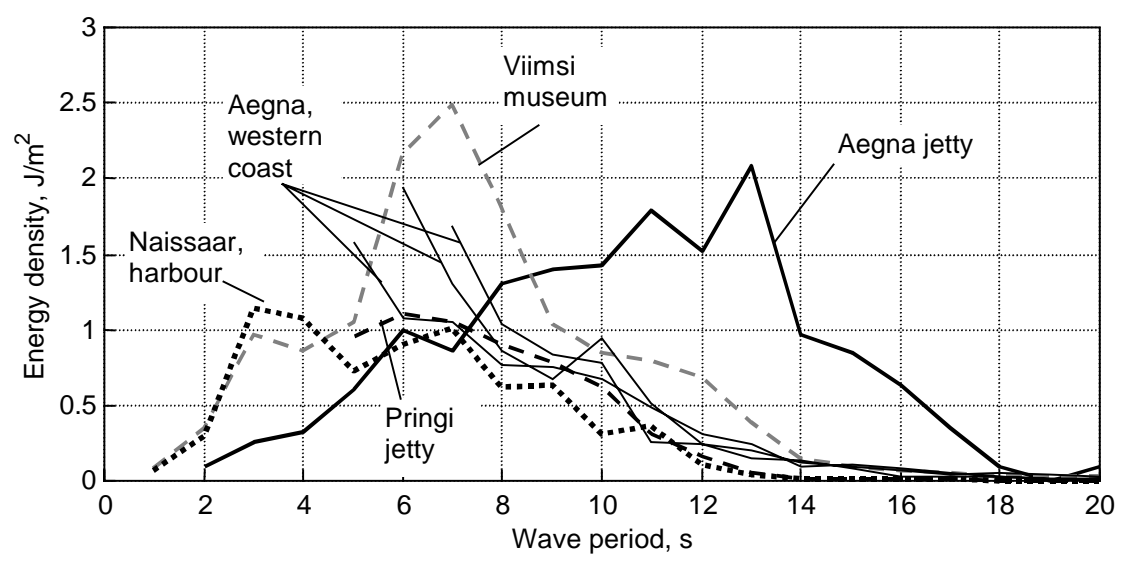

Fig. 3. Energy of wash components with different periods. The resolution is $1 \mathrm{~s}$. At the western coast of Aegna and at Pringi jetty, the contribution of wind waves is notable already for periods of 5-6 s and energy of shorter waves is not shown. A peak at 3-4s in the Naissaar and Viimsi museum data corresponds to wind waves. The data at Aegna jetty were recorded in perfectly calm conditions and represent ship waves up to the smallest periods. 
The energy distribution between wave components is greatly different at different sites. The largest fraction (77\%) of energy in waves with periods $>8 \mathrm{~s}$ was recorded at Aegna jetty. This area receives a large portion of high and extremely long waves with periods exceeding $10 \mathrm{~s}$. The average spectral energy density had the most sharply peaked shape. The periods of the most energetic waves were the largest (13-14 s and 10-11 s) at this site suggesting that this area is frequently directly hit by the remnants of the single bow wave.

Other sites are affected by somewhat shorter waves. In the neighbouring area at the western coast of Aegna, wave energy is mostly concentrated in components with periods $\leq 10 \mathrm{~s}$. Moderate prevailing periods (about $7 \mathrm{~s}$ ) near Pringi jetty evidently show that waves reaching this area have been mostly excited by ships sailing at relatively low speeds. At Naissaar, the energy of waves with periods of 6-10 s was comparable with that in the other sites. However, the portion of even longer waves was relatively small, apparently owing to wave-bottom interaction of long waves in the sea area between the ship lane and Naissaar. Also, the coastal zone of Naissaar generally does not receive much transverse wave energy.

\section{COMPARISON OF SHIP WAKES AND WIND WAVES}

The above has shown that the waves caused by large fast ferries generally are higher than those excited by hydrofoils or conventional ferries. The heights of the wake waves of fast ferries (normally not exceeding $1 \mathrm{~m}$ ) are moderate in the coastal zone of Tallinn Bay compared with the highest wind waves reaching this area every year (significant wave height $H_{\mathrm{s}} \sim 1.5 \mathrm{~m}$, i.e., the highest single waves are about $3 \mathrm{~m}$ high). However, wind waves of this height occur infrequently and the highest daily examples of ship-generated waves belong to the highest $1-5 \%$ of wind waves (except near Naissaar, Fig. 4).

The impact of waves can be quantified in terms of wave energy, e.g., with the use of the integral energy density in the water column per unit of the sea surface. The number of wave crests of a single ship wake and its energy are indeed small compared with waves occurring during strong storms. Yet the fast ferry traffic is so heavy that ship waves do play a notable role in the wave energy balance. Based on data from $\left[{ }^{28,32,33}\right]$, the mean energy of ship-generated waves at the $5 \mathrm{~m}$ isobath was estimated as 5-8\% from the annual mean wind wave energy and 6$12 \%$ from the wave energy during the spring and summer seasons (Fig. 4). Only in a few coastal areas (that are open to the dominating wind directions, e.g. the western coast of Aegna), the ship wave energy is about 3.5\% from the annual and $5 \%$ from the summer mean wave energy. Since wind waves propagate frequently towards the open sea, but the ship waves do not, the relative role of ship waves in the total wave activity is indeed more significant.

Solely energy-based comparison of waves of different origin obviously is incomplete because it is equivalent to a comparison of the squared wave heights 
(a)

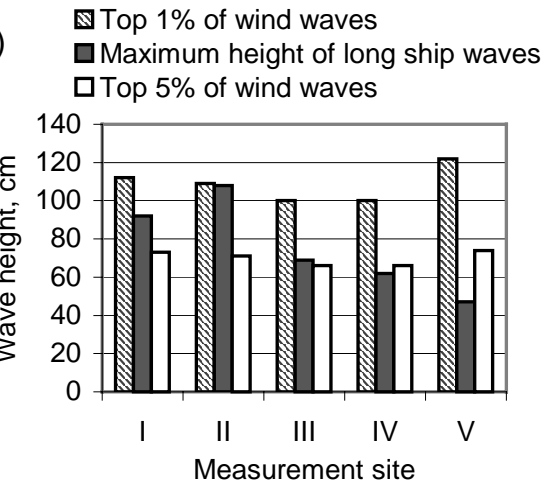

(b)
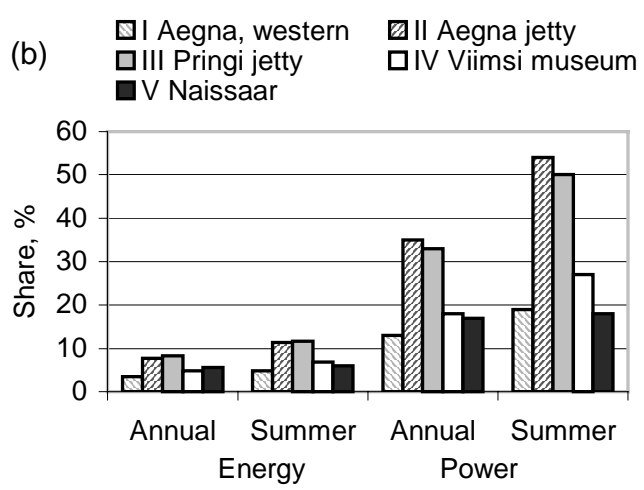

Fig. 4. (a) Comparison of the daily maximum heights of the long-term components with periods $>7 \mathrm{~s}$ of the wake waves of the fast ferries with the significant heights of wind waves occurring with the probability of 1 and 5\%; (b) comparison of wake energy and its flux (wave power) with the wind wave energy and its flux round the year and during the spring and summer seasons. For the measurement site at the western coast of Aegna, the average values of three measurement days from $\left[{ }^{33}\right]$ have been used.

and does not take into account other wave properties. Since the most energetic ship waves are longer than wind waves, the energy-based comparison may considerably underestimate the role of ship waves in the nearshore environment.

Wave energy propagates with the group speed. The product of the wave energy density and group speed is the density of energy flux (bulk power carried by the wave per unit of length of wave crests). This quantity implicitly accounts for the wave periods since longer waves have higher group velocities. For wind wave fields, it was assumed that the wave energy propagates with the group velocity of the wave with maximum energy $\left[^{32}\right]$. For ship wakes, it was assumed that energy propagates with the group velocity of the wave, which frequency equals to the mean weighted frequency of the wake $\left[{ }^{33}\right]$.

The difference of the prevailing periods of the highest parts of ship waves causes their much higher portion in terms of energy flux (wave power). The annual mean bulk power of ship waves in the coastal area of Tallinn Bay is $\left.50-100 \mathrm{~W} / \mathrm{m}^{33}\right]$. It constitutes $18-35 \%$ from the total wave power at the western coast of the bay, about 13\% in areas open to the Gulf of Finland, and about 17\% at the eastern coast $\left[{ }^{32}\right]$. Owing to strong seasonal variation of the natural wave regime, the power of ship waves forms up to $54 \%$ of the power of wind waves. Since the wave propagation direction is not included in the calculations, the ship waves may cause approximately one third to a half of the wave power at the coasts of the bay during the spring and summer seasons.

The difference of prevailing periods of the highest parts of the ship wash and the windseas is the most critical issue in the area in question $\left[{ }^{35}\right]$. A seemingly insignificant contrast between the prevailing periods of natural waves (3-4 s during moderate winds and up to $7 \mathrm{~s}$ during extreme storms) and ship waves (mostly exceeding $8 \mathrm{~s}$; frequently 10-15 s) causes highly dissimilar impact of the waves of different origin at medium depths $(5-20 \mathrm{~m})$. 
The reason is that for a fixed wave height, the wave-induced near-bottom velocity of water particles depends essentially on the wave period. For the mentioned depths, the highest variation of this velocity occurs when the wave period increases from 5 to $8 \mathrm{~s}$ (Fig. 5). A typical ship wave with the height of $1 \mathrm{~m}$ and period of $10 \mathrm{~s}$ induces the near-bottom velocity as high as about $45 \mathrm{~cm} / \mathrm{s}$ at the depth of $10 \mathrm{~m}$ whereas the maximum velocity created by a wind wave with the period of $4 \mathrm{~s}$ is only a few $\mathrm{cm} / \mathrm{s}$. Thus, in terms of near-bottom velocity, the impact of a typical ship wake component on bottom sediments and aquatic wildlife is equivalent to the waves occurring in extreme storms.

This point becomes evident from the comparison of the heights of long components of typical ship waves and wind waves occurring during relatively strong storms. The summer gale on June 21, 2002 created particularly rough seas. The significant wave height exceeded $2 \mathrm{~m}$ and reached its 1-year return value in many parts of Tallinn Bay. However, the amplitudes of the long components of the ship waves were comparable with those of the wind waves even in very rough seas during this storm (Fig. 6; cf. also Fig. 11 of $\left[{ }^{33}\right]$ ). The maximum heights of natural wave components with periods $>7 \mathrm{~s}$ were about $70-75 \mathrm{~cm}$ during a short time interval at the storm maximum, thus clearly less than the daily maximum amplitudes of long ship waves.

This difference in wave periods becomes first evident in sediment transport processes. Since the ship waves have moderate heights, they normally do not affect the backshore (like extreme storm waves do) and their influence is limited by the shoreline. Also, fast ferries sail more intensively during the spring and the summer seasons when generally the low water level dominates, therefore their wakes affect even deeper parts of the seafloor.

Below the waterline, waves can carry sediment material in different ways $\left.{ }^{[3,54}\right]$. Currents and turbulence raise the suspended sediment particles above seafloor and carry it forward. As different from storm waves, in the case of fast ferry

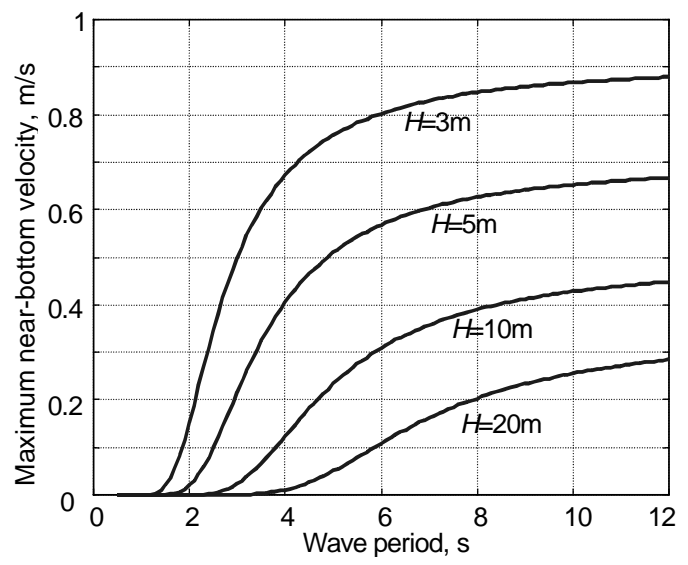

Fig. 5. The maximum wave-induced near-bottom velocity versus wave period for the wave height of $1 \mathrm{~m}$ and the water depth $H=3-20 \mathrm{~m}$. 


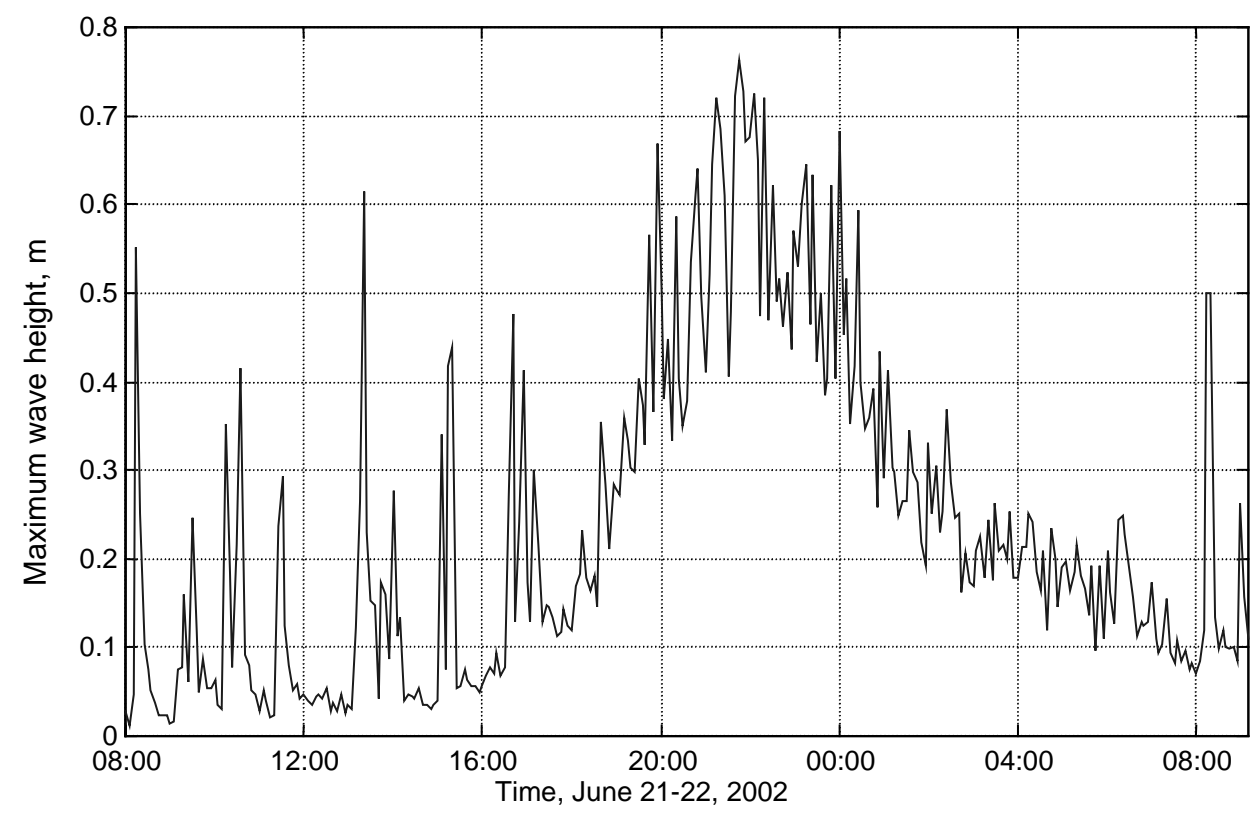

Fig. 6. The maximum amplitudes of waves with periods $>7 \mathrm{~s}$ during the summer gale 21.22.06.2002. The temporal resolution is $5 \mathrm{~min}$. The sharp peaks until 18:00 of June 21 and starting from 08:00 of June 22 represent wakes of fast ferries.

waves formation of longshore currents is unlikely, since the duration of wave packages $\left[{ }^{33}\right]$ is too short $\left[{ }^{14}\right]$. Thus, sediment transport by fast ferry waves generally occurs in the direction of wave propagation, that is, roughly perpendicular to the shoreline $\left[{ }^{14}\right]$.

Owing to considerable seasonal variation of the dominating wind directions in the area in question, the longshore sediment movement, jointly induced by ferry waves and nearshore currents during the high navigation season, may be oppositely directed compared to that occurring due to severe wind waves $\left[{ }^{28}\right]$. This quite delicate and interesting effect may even somewhat reduce the intensity of natural beach processes in some coastal areas, in particular, the total intensity of transport of fine sediments towards the bayhead.

Orbital velocity under the wave crest is higher than under the wave trough, consequently more sediments are brought into motion under the wave crest and are carried with the crests to some extent. A part of water involved in waves moves in the direction of wave propagation, resulting in sediment transport in the same direction. This transport, owing to ship waves is probably more intense than the one created by wind waves, since the ship waves are often asymmetric $\left[{ }^{14,33}\right]$. The asymmetry of wave profiles leads to a differential net transport scheme where finer sediments move downslope (offshore) and larger particles onshore $\left[{ }^{55}\right]$. 
Due to the excessive length of the waves of fast ferries, they often break relatively far from the waterline. Breaking waves effectively suspend sediments that are normally transported offshore by the backwash (e.g., $\left[{ }^{55}\right]$ ). These mechanisms are not necessarily active in the deeper part of the coastal zone in natural conditions. Their abrupt intensification may cause considerable changes in the existing balance of sediment distribution $\left[{ }^{35}\right]$.

\section{CONCLUSIONS AND DISCUSSION}

The role of ship waves is small in terms of energy ( $10 \%$ from the bulk wave energy) but pretty large in terms of energy flux (equivalent to wave-induced power). The share of ship waves represents $18-35 \%$ (27-54\% during the summer season) from the total wave power at the western coast of Tallinn Bay.

Analysis of the geological setting and nearshore processes in the Tallinn Bay area shows that usually ship waves do not cause direct shoreline erosion. Generally deposits are covered with a pebble and cobble pavement which protects the shore from further erosion. Ferry-generated waves still have modest heights $(\sim 1 \mathrm{~m})$ and are not able to erode these shores considerably. The changes in the near- and backshore during the observation period (summer 2001-autumn 2002) were mostly due to the autumn-winter storms. Thus, the wakes of fast ferries apparently play a rather insignificant role in the vicinity of the shoreline.

Long periods of the highest parts of ship wakes is a really critical issue when comparing the influence of wind and ship waves in the area in question. The major influence of the long-wave components apparently becomes evident in relatively deep areas. Owing to excessive wave lengths, ship wakes cause unusually high near-bottom velocities at the depths of 5-30 m. Consequently, waves of different origin probably transport sediment material at different water depths. The abrupt increase of hydrodynamic activity in the deeper part of the nearshore may considerably change the existing sediment transport balance $\left[{ }^{35}\right]$. In the long run, this may notably accelerate beach processes, because already relatively small levels of long-period swell energy in combination with wind waves can cause greater beach response than an equal amount of energy in the windsea frequencies $\left[{ }^{56}\right]$. This hypothesis is indirectly confirmed by the greatly reduced water transparency of sea water owing to the wakes of fast ferries that has been frequently an object of complaints by fishermen $\left[{ }^{28}\right]$.

In particular, the anthropogenic wave-induced component of near-bottom velocity may dominate during the relatively calm high navigation season (AprilSeptember) when the biological productivity is at its seasonal maximum. The impact of long components of ship wakes on bottom sediments and aquatic biota, in particular, in the deeper part of the coastal area, is comparable with the waves occurring in extreme storms. Many components of the marine system, historically, have been adjusted to low near-bottom velocities, thus the fast ship waves appear as a new forcing component of the ecosystem of the bay. The reduced water 
transparency, besides of the impact of direct mechanical disturbances, may have suppressing feedback on the bottom vegetation. Suspension and re-sedimentation of finer sediments may considerably worsen fish spawning conditions. Another potential mechanical effect of ship waves is the enhancement of vertical mixing along the ship lane that may intensify the eutrophication effects and influence harmful algae blooms due to the transport of nutrients from sediments into the euphotic layer.

The shape of the pressure signal suggests that the leading wake waves apparently are asymmetric: the crest elevation clearly exceeds the depth of the trough $\left[{ }^{28,33}\right]$. (Relevant measurements were performed in September $2001\left[^{57}\right]$ but the results are neither published nor available by other means). This property means that the actual near-bottom velocities created by ship waves may essentially exceed the estimates of the linear theory. The slope of the water surface in these waves may exceed that in wind waves, making ship waves more dangerous for small boats, in particular, in cases when a part of dangerous waves may arrive sometimes many tens of minutes after the leading waves.

An important issue is that the ship waves are examples of extremely strong impulse loads that (in specific parts of the bay and/or during certain seasons) may essentially exceed similar loads caused by natural factors. For example, there might well exist situations where a ship wake suspends all potentially available sediment fractions. In such situations, it does not matter if just one wake or a strong storm with hundreds of waves occurs in a certain time interval. This feature is particularly important for effects with large relaxation times such as changes in underwater light climate caused by extensive resuspension of fine sediments in large sea areas.

\section{ACKNOWLEDGEMENTS}

The study was mostly performed in the framework of the project "The influence of ship wakes on beaches of the Viimsi Peninsula and Naissaar and Aegna islands, and the possibilities of its neutralizing" (financed by the Estonian Environmental Investments Centre) and partially supported by the Estonian Science Foundation (grant No. 4025).

\section{REFERENCES}

1. Sörensen, R. M. Ship-generated waves. Adv. Hydrosci., 1973, 9, 49-83.

2. Chen, X.-N. and Sharma, S. On ships at supercritical speeds. In 21th Symposium on Naval Hydrodynamics. Trondheim, 1996. National Academy Press, Washington, D. C., 1997, 715-726.

3. Kofoed-Hansen, H. and Kirkegaard, J. Technical Investigation of Wake Wash from Fast Ferries. Report No. 96-5012, Danish Hydraulic Institute, Copenhagen, 1996.

4. Hansen, P. H. Solitary killers. New Scientist, 1999, No 163(2201), 18-19. 
5. Doctors, L. J., Phillips, S. J., and Day, A. H. Focussing the wave-wake system of a high-speed marine ferry. In Proc. 6th International Conference on Fast Sea Transport FAST 2001. Southampton, 2001. RINA, London, 2001, vol. 1, 97-108.

6. Kofoed-Hansen, H. and Mikkelsen, A. C. Wake wash from fast ferries in Denmark. In Fourth International Conference on Fast Sea Transportation. Sydney, 1997. Baird Publications, Hong Kong, 1997, vol. 1, 471-478.

7. Kirk McClure Morton. Investigation of High Speed Craft on Routes Near to Land or Enclosed Estuaries. Res. Report JR226. The Maritime and Coastguard Agency, UK, 1998.

8. Forsman, B. High-speed ferries - environmental impact and safety assessment. PIANC Bull., 1997, No. 96, 23-24.

9. Forsman, B. From bow to beach. SSPA Highlights, 2001, No. 3, 4-5.

10. Parnell, K. E. and Kofoed-Hansen, H. Wakes from large high-speed ferries in confined coastal waters: Management approaches with examples from New Zealand and Denmark. Coastal Manag., 2001, 29, 217-237.

11. Hannon, M. and Varyani, K. S. The wash effect of high speed ferries in coastal and inland waterways. In Proc. International Conference on Coastal Ships and Inland Waterways. London, 1999. RINA, London, 1999 (CD).

12. A Technical Protocol for the Assessment of Abnormal Wave (Wash) Effects Generated by High Speed Craft (HSC) and Ships. Memorandum MECP 45/INF.19, 28.07.2000. International Maritime Organization, London, 2000.

13. Kirkegaard, J., Højtved, N., and Holmegaard Kristensen, H. O. Fast ferry operation in Danish waters. In 29th International Navigation Congress. The Hague, 1998. International Navigation Association (PIANC), Brussels, 1998, 5-12.

14. Kirkegaard, J., Kofoed-Hansen, H., and Elfrink, B. Wake wash of high-speed craft in coastal areas. In Coastal Engineering 1998: Proc. 26th International Conference. Copenhagen, 1998 (Edge, B. L., ed.). American Society of Civil Engineers, 1999, vol. 1, 325-337.

15. Kofoed-Hansen, H., Jensen, T., Sørensen, O. R., and Fuchs, J. Wake Wash Risk Assessment of High-speed Ferry Routes - a Case Study and Suggestions for Model Improvements. Report No. 2000/52. Danish Hydraulic Institute, Copenhagen, 2000.

16. Varyani, K. S. and Krishnankutty, P. Wave Wash of Stena Explorer in Dublin Bay. Wave Wash of NGV Liamone in Nice Port. Wave Wash of INCAT96 in Barcelona. EU Project TOHPIC, Documents No. 1.2.08.01, 1.2.08.02, and 1.2.08.03. January, 2002.

17. Zibell, H. G. and Grollius, W. Fast vessels on inland waterways. In Proc. International Conference on Coastal Ships and Inland Waterways. London, 1999. RINA, London, 1999 (CD).

18. Macfarlane, G. J. and Renilson, M. R. Wake wave - a rational method for assessment. In Proc. International Conference on Coastal Ships and Inland Waterways. London, 1999. RINA, London, 1999 (CD).

19. Koushan, K., Werenskiold, P., Zhao, R., and Lawless, J. Experimental and theoretical investigation of wake wash. In Proc. 6th International Conference on Fast Sea Transport FAST 2001. Southhampton, 2001. RINA, London, 2001,vol. 1, 165-179.

20. Feldtmann, M. and Garner, J. Seabed modifications to prevent wake wash from fast ferries. In Proc. International Conference on Coastal Ships and Inland Waterways. London, 1999. RINA, London, 1999 (CD).

21. Bolt, E. Fast ferry wash measurement and criteria. In Proc. 6th International Conference on Fast Sea Transport FAST 2001. Southhampton, 2001. RINA, London, 2001, vol. 1, 135148.

22. Orviku, K. Ekspertarvamus Aegna saare lääneranniku randade looduslikust seisundist. Manuscript, 08.09.2000.

23. Launiainen, J. and Laurila, T. Marine wind characteristics in the northern Baltic Sea. Finnish Marine Res., 1984, 250, 52-86.

24. Donelan, M. A., Hamilton, J., and Hui, W. H. Directional spectra of wind-generated waves. Philos. Trans. Royal Soc. London, 1985, A315, 509-562. 
25. Pettersson, H., Kahma, K., and Tuomi, L. Predicting wave directions in a narrow bay. J. Phys. Oceanogr. Forthcoming.

26. Soomere, T. and Keevallik, S. Directional and extreme wind properties in the Gulf of Finland. Proc. Estonian Acad. Sci. Eng., 2003, 9, 73-90.

27. Alenius, P., Myrberg, K., and Nekrasov, A. The physical oceanography of the Gulf of Finland: A review. Boreal. Env. Res., 1998, 3, 97-125.

28. Soomere, T., Elken, J., Kask, J., Keevallik, S., Kõuts, T., Metsaveer, J., and Peterson, P. Laevaliikluse purustav mõju Viimsi poolsaare, Aegna ja Naissaare randadele ning selle neutraliseerimise võimalused. Res. Report. Marine Systems Institute at Tallinn Technical University, Tallinn, 2002.

29. Kask, J., Talpas, A, Kask, A., and Schwarzer, K. Geological setting of areas endangered by waves generated by fast ferries in Tallinn Bay. Proc. Estonian Acad. Sci. Eng., 2003, 9, 185-208.

30. Keevallik, S. Tallinna lahe tuuled. Publicationes Instituti Geographici Universitatis Tartuensis, 2003, 93, 217-226.

31. Keevallik, S. Possibilities of reconstruction of the wind regime over Tallinn Bay. Proc. Estonian Acad. Sci. Eng., 2003, 9, 209-219.

32. Soomere, T. Tallinna lahe loodusliku lainetuse režiimist. Publicationes Instituti Geographici Universitatis Tartuensis, 2003, 93, 227-241.

33. Soomere, T. and Rannat, K. An experimental study of wind waves and ship wakes in Tallinn Bay. Proc. Estonian Acad. Sci. Eng., 2003, 9, 157-184.

34. Peterson, P., Soomere, T., Engelbrecht, J., and van Groesen, E. Soliton interaction as a possible model for extreme waves in shallow water. Nonlinear Proc. Geophys., 2003. Forthcoming.

35. Soomere, T. and Kask, J. A specific impact of waves of fast ferries on sediment transport processes of Tallinn Bay. Proc. Estonian Acad. Sci. Biol. Ecol., 2003, 52, 319-331.

36. Niros, A., Vihma, T., and Launiainen, J. Marine meteorological conditions and air-sea exchange processes over the northern Baltic Sea in 1990s. Geophysica, 2002, 38, 59-87.

37. Talpas, A., Kask, J., Mardla, A., Väling, P., and Sakson, M. Balti mere šelfiala geoloogiline kaardistamine mõótkavas 1 : 200 000. Map sheets 0-34-VI, 0-34-XII, 0-35-I, II. Res. Report, Geological Survey of Estonia, Tallinn, 1994.

38. Froude, W. Experiments upon the effect produced on the wave-making resistance of ships by length of parallel middle body. Trans. Inst. Naval Arch., 1877, 18, 77-87.

39. Thomson, W. (Lord Kelvin). On ship waves. Trans. Inst. Mech. Eng., 1887, 409-433.

40. Havelock, T. H. The propagation of groups of waves in dispersive media, with application to waves on water produced by a travelling distance. Proc. Roy. Soc. London, Ser. A, 1908, 81, 398-430.

41. Basin, A. M. and Anfimov, V. N. Ship Hydrodynamics. Rechnoj Transport, Leningrad, 1961 (in Russian).

42. Hüsig, A., Linke, T., and Zimmermann, C. Effects from supercritical ship operation on inland canals. J. Waterway, Port, Coastal Ocean Eng., 2000, 126, 130-135.

43. Research project 457: A Physical Study of Fast Ferry Wash Characteristics in Shallow Water. Marine Information Note MIN $118(\mathrm{M}+\mathrm{F})$. Marine and Coastguard Agency, Southampton, 2001.

44. Li, Y. and Raichlen, F. Solitary wave runup on plane slopes. J. Waterway, Port, Coastal Ocean Eng., 2001, 127, 33-44.

45. Freeman, N. C. Soliton interactions in two dimensions. Adv. Appl. Mech., 1980, 20, 1-37.

46. Miles, J. W. Note on solitary wave in a slowly varying channel. J. Fluid Mech., 1977, 80, 149152.

47. Whittaker, T. J. T., Doyle, R., and Elsäßer, B. An experimental investigation of the physical characteristics of fast ferry wash. In 2nd International EuroConference on HighPerformance Marine Vehicles HIPER'01. Hamburg, 2001. Technical University MamburgHarburg, 2001, 480-491.

48. Grimshaw, R., Pelinovsky, D., Pelinovsky, E., and Talipova, T. Wave group dynamics in weakly nonlinear long-wave models. Physica D, 2001, 159, 35-57. 
49. Orlenko, L. R. (ed.) Studies of the Hydrometeorological Regime of Tallinn Bay. Gidrometeoizdat, Leningrad, 1984 (in Russian).

50. Order on the Approval of the Safe Navigation of High-Speed Ferries No. 307 of 1 May 1997. http://www.dma.dk/sw221.asp (accessed 13.06.2003).

51. Navigation Bylaw 2000. http://www.marlborough.govt.nz/harbour/bylaws_main.asp (accessed 13.06.2003).

52. International Code of Safety for High-speed Craft (HSC Code). Adopted by the Maritime Safety Committee (May 1994), resolution MSC 36(63). International Maritime Organization, London, 1994.

53. Soulsby, R. Dynamics of Marine Sands. A Manual for Practical Applications. Thomas Telford Publications, London, 1997.

54. Coastal Engineering Manual. Department of the Army. U.S. Army Corps of Engineers. Manual No. 1110-2-1100, 2002 (CD).

55. Carter, R. W. G. Coastal Environments. Academic Press, London, 2002.

56. Coates, T. T. and Hawkes, P. J. Beach recharge design and bi-modal wave spectra. In Coastal Engineering 1998: Proc. 26th International Conference. Copenhagen, 1998 (Edge, B. L., ed.). American Society of Civil Engineers, 1999, vol. 3, 3036-3045.

57. Peltoniemi, H., Bengston, A., Rytkönen, J., and Kõuts, T. Measurements of fast ferry waves in Helsinki-Tallinn route. In Symposium "The Changing State of the Gulf of Finland Ecosystem”. Tallinn, 2002. Abstracts, Estonian Ministry of Environment, Tallinn, 2002, 32.

\section{Kiirlaevaliiklus uue võtmetegurina Tallinna lahel}

\section{Tarmo Soomere, Jüri Elken, Jüri Kask, Sirje Keevallik, Tarmo Kõuts, Jaan Metsaveer ja Pearu Peterson}

On analüüsitud laevade käigulainete osa lainetusest põhjustatud protsessides Tallinna lahel. Laevalainete kõrgused on üldiselt väiksemad kui tormilainetel. Rannajoone vahetus läheduses on merepõhi enamasti kaitstud munakivide ja veeriste kihiga ning laevalainete mõju on seal väike. Kuna laevaliiklus lahel on väga tihe, kuid loodusliku lainetuse režiim suhteliselt mahe, moodustab laevalainete energia 5-8\% tuulelainete energiast ning 18-35\% nende võimsusest. Kiirlaevade käigulainete kõrgeimate komponentide kõrgused ületavad sageli $1 \mathrm{~m}$ ning nende perioodid on vahemikus 10-15 s. Sellised lained, milliseid looduslikes tingimustes Tallinna lahel ei esine, põhjustavad ebaharilikult tugevaid põhjalähedasi hoovuseid sügavustes 5-20 m. Kiirlaevaliiklus on seega kujunemas lahe ökosüsteemi uueks võtmeteguriks, mis võib oluliselt modifitseerida nii rannaprotsesside kulgu ja hüdrodünaamiliste väljade kujunemist kui ka vee-elustikku. 